\title{
INTRODUCTION TO THE EDITOR'S COLUMN
}

\author{
Rachel Conrad \\ Professor, Hampshire College
}

$\mathrm{I}_{\mathrm{N}}$ THINKING about young writers, trauma, and intersectionality, it is crucial to recognise young people's agency in conceptualising, naming, and navigating experiences of trauma. How do we know whether and how children consider events of their lives to be traumatic and what that means to them, and how do such experiences and meanings interact with their identities, including their identity as young? We need to take care to recognise contexts of trauma that may frame children's experiences, yet not assume that children who have lived their lives within and alongside potentially traumatic situations are necessarily traumatised. Certain events are potentially traumatic, but children may experience the same event in quite different ways. Each child constructs her own meaning from her experiences, even in the face of trauma. It is also important to acknowledge potentially traumatic situations that are not recognised as such by dominant societal discourses and institutions. In juvenilia studies, we have a window onto young writers' constructions and representations that helps us explore or even reframe these questions.

Young poet Vanessa Howard, a participant in The Voice of the Children workshop directed by poet June Jordan and educator Terri Bush in Brooklyn in the late 1960s and early 1970s, constructs in her extended poem "The Last Riot" the stark landscape of a race riot that seems poised at the precipice of apocalypse: "When black and white will match their wits / and take this human race to bits." Howard's poem, published in the 1970 anthology THE VOICE of the Children (collected by Jordan and Bush), begins, "Tension in the heat-filled night / The coming of a racist fight" (8), and the opening word "Tension" as well as the definitive rhyme of "night" with "fight" signal the combination of complexity, clarity, and finality of this evocation of a race riot. As the poem advances, it describes moving beyond "trying to care" and beyond "hurt and fear" to "One last fight" and the start of explicit violence- "A cut of flesh a cry of pain" - that is elemental and beyond punctuation. The violence that erupts from "hatred" wreaks large-scale devastation: "All lives to be drowned in a

(cc) Conrad. This article is distributed under a Creative Commons Attribution-NonCommercialNoDerivatives 4.0 International Licence (creativecommons.org/licenses/by-nc-nd/4.0/).

Journal of Juvenilia Studies 4.I (202I), Pp. 3-8. DOI: 10.29I73/jjs72 


\section{JJS December (202I) Special Issue: Juvenilia, Trauma, and Intersectionality}

pool of blood / Brought on by a hatred flood" (8). In the poem's second and final section, the ageless speaker breathlessly describes the "last riot" (9) again yet in intensified close-up, with violence being visited on "Children bleeding screaming fearing" before the "Bombs" arrive, whereupon even the "Last baby drops / ... Last of the human race" (9). Not only are children not held in that space, they are "drop[ped]": they fall out of the space that adults have made (or broken). In what ways is this stark and graphic imagery of racial violence a depiction of trauma? In what ways is it an unsparing depiction of realities of racial violence? What are the benefits of referring to it as a representation of trauma, and what are the limitations? In this introduction, I raise these and other questions to invite us to explore complex dynamics of trauma, intersectionality, and juvenilia, as do the writers of the essays that follow.

Trauma itself can be a totalising lens that circumscribes and constricts our view of children's experiences. A child in the act of writing can try to write about, around, over, through, or beyond the constraints of trauma itself. Howard's speaker in "The Last Riot" reads as a lone survivor, as either the "Last of the human race" evoked in the poem's final line or as a presence who has already witnessed the death of humanity. As a young Black poet, Howard crafts her own "terrible beauty" from US racial conflict, to use that bitter phrase from Yeats's poem "Easter 1916" that describes revolutionary possibilities emerging alongside the death of Irish nationalists during the Easter Rising against British rule. How are the multiple and intersecting aspects of a young person's identity—including age — connected to the potential for exposure to trauma, to how a young person ascribes trauma to her experience, to how others ascribe it to her, and to how a young person constructs meaning and makes art from, through, and beyond her experiences?

In thinking about trauma and intersectionality, we run up against immediate roadblocks in standard conceptualisations. The dominant psychiatric understanding of trauma, as delineated in the American Psychiatric Association's current Diagnostic and Statistical Manual of Mental Disorders (DSM-5), does not account for the range of experiences of racism and other forms of oppression. Potentially traumatic events are specified in DSM-5 as "actual or threatened death, serious injury, or sexual violence" (271), and thus the psychological effects of racism and other forms of oppression as stressors are not included in standard psychiatric models of trauma. Robert T. Carter works against such limitations by pursuing a robust and influential line of scholarship on race and discrimination in relation to trauma, efforts which depend on "introducing new ways to recognize and assess race-based stress and trauma" (17). Carter argues that a "race-specific mental health standard" is needed through which to think about the experiences of people of color, and he proposes the notion of "race-based traumatic stress injury" as "a nonpathological category" that can nevertheless "be used by mental health professionals to identify and assess people of Color's encounters with racism that produce stress and trauma" (96). Carter defines

"race-based traumatic stress injury" as "involv[ing] emotional or physical pain or the 


\section{Editor's Column | Conrad}

threat of physical and emotional pain that results from racism in the forms of racial harassment (hostility), racial discrimination (avoidance), or discriminatory harassment (aversive hostility)" (88), and he emphasises the "nonpathological" nature of this category in order to recognise many possible forms of "psychological harm from racism" (93) that may not be clinically severe. While much still needs to be determined in clinical psychological research on and assessment of such aspects as "how specific encounters with racism become traumatic" (95), a first step is to recognise race-related stress as part of the landscape of potential trauma. This is but one example of the conceptual work needed to support our thinking about intersectionality, trauma, and juvenilia.

The concept of intersectionality itself-first delineated by Kimberlé Crenshaw in the late 1980s-began as a "heuristic term to focus attention on the vexed dynamics of difference and the solidarities of sameness in the context of antidiscrimination and social movement politics" (Cho, Crenshaw, and McCall, 787). While age-related (child/adult) status is not commonly invoked in discussions of intersectionality, it certainly can and should be, as it is relevant to intersectionality's "generative focus as an analytical tool to capture and engage contextual dynamics of power" (788). In other words, intersectionality is an "analytical sensibility" (795), a way of thinking about power in relation to difference and sameness, that involves "conceiving of categories not as distinct but as always permeated by other categories, fluid and changing, always in the process of creating and being created by dynamics of power" (795).

A crucial aspect of attention to these questions involves thinking critically about the nature of our access to young people's perspectives, words, and ideas in relation to intersectionality and trauma. For instance, LaKisha Simmons has written about the challenges of finding work by young Black writers (and Black girls in particular) in archives- "searching for girls' own articulations of the pain of growing up in the storm of southern American violence" (449)—since the words "children" and "girls" were racially coded in the US South. As Simmons writes, "in the official archive of the segregated South, 'child' or 'girl' refers only to white children or white girls. To find black girls, I could not go to a catalogue card that read "children"' (457). Simmons articulates the layering of "disregard" (450) for the lives and perspectives of Black girls, both "in their own time and then again by record-keepers and archivists" (450). One strategy that Simmons pursued was to search the papers of historically Black colleges and universities (HBCUs) or other archives where adults (e.g., teachers and social workers) would have interacted with Black girls and might have preserved their words and work. Such a promising approach models the persistence and ingenuity required to recover voices of marginalised young people in order to enrich our literary cultures.

In the Editor's Column of this special issue, I invited authors to explore complexities of trauma, intersectionality, and juvenilia through focusing on a youthauthored text. The result is a fascinating and provocative set of five essays, which are 


\section{JJS December (202I) Special Issue: Juvenilia, Trauma, and Intersectionality}

from different disciplinary perspectives, attend to a range of historical and geographical locations, and focus on young writers who are from marginalised backgrounds and/or are not typically at the center of scholarly attention. This combination of essays enables us to consider, reconsider, and potentially reframe our questions about young people's experience and writings in relation to trauma and intersectionality. I express my gratitude to the writers of these essays for their compelling and incisive engagement with the focus of this Editor's Column, and to the editors of the Joumal of Juvenilia Studies for extending the invitation to me to serve as Guest Editor of this issue.

In "Trauma in Phillis Wheatley's Juvenilia," Lucia Hodgson considers eighteenth-century American poet Phillis Wheatley, the first African American poet to publish a volume of poetry, and explores "her agency in grappling with how to represent her traumatic childhood experiences." She examines a key poem by Wheatley as a work of juvenilia, and reads related letters by Wheatley in order to "complicate the unanswerable question of whether she couldn't remember her childhood ... or whether she chose not to share those memories in her written work." Hodgson discusses Honorée Fanonne Jeffers's recent poetry collection The Age of Pbillis as "likely ... a significant turning point in Wheatley scholarship with regard to perceptions of trauma in her writings," and she illuminates the importance of recognising that "to understand Wheatley's writing requires recognition of her agency in representing traumatic childhood experiences while also navigating the circumstances of her enslavement."

In "Child Journalists, the Civil War, and the Intersectional Work of Reporting Grief," Sara Danger introduces a daily newspaper edited by three young white Northern sisters in the late nineteenth century during the US Civil War, and illuminates how they used journalistic forms to write about their brother's capture and death. Danger examines how the Williams sisters shaped their reporting on their brother's circumstances in editorials they authored in the popular weekly newspaper they edited, as well as in a related periodical they edited and produced. She also calls attention to their incorporation of elegiac poems written by others alongside their own journalistic prose as means of establishing an interplay across genres that worked with and against established conventions of grief.

In "Child Writing and the Traumatised Body," Caroline Lieffers explores a memoir written by a young victim of the atomic bombing of Nagasaki, Japan in 1945 at the end of the second World War. She frames her focus on Ishida Masako's representations of bodily pain and trauma as a young survivor of war and violent conflict through the approaches of history of childhood emotion and disability studies. The questions Lieffers asks prompt us to consider how "young people experience, understand, and cope with damage to their bodies," how they use writing to depict and make sense of injury, what stigma they also face, and ultimately how they write about such experiences and—on cultural and political dimensions- how 


\section{Editor's Column | Conrad}

such young writers "negotiate the meanings that such prose held within societies and cultures that had undergone collective trauma and transformation."

In "Collaboration and Connection: Intergenerational Authorship in Al Rabeeah and Yeung's Homes: A Refugee Story," Rachel Conrad and Lesley Peterson consider a text produced through "collaboration and connection" between Abu Bakr al Rabeeah, a young refugee from violent conflict in Syria, and Winnie Yeung, his English as a Second Language teacher in Canada (herself an immigrant from China), who crafted a book of "creative nonfiction" following a careful interview process with al Rabeeah and his family. Through a joint interview with al Rabeeah-now a young adult — and his former teacher Yeung, Conrad and Peterson explore the nature of this intergenerational collaboration between al Rabeeah as "the storyteller" and Yeung as "the writer," with al Rabeeah "guiding the conversation" yet Yeung responsible for crafting the organisation, prose, and voice of the book itself. Yeung concludes the interview with a note of caution about expecting young people to write about trauma and emphasises the importance of young people's choice and direction.

Finally, in “'Because I Won't Ever Forget': Towards Livingness in Youth Poetry," Alisha Jean-Denis and Korina Jocson raise crucial concerns about young people, trauma, writing, and pedagogy in light of "histories of colonialism, enslavement, and dehumanization." They discuss poetry and other cultural forms as "counter-expressions" that "offer creative outlets to break free [from] the imposed silences/silencing within systems of oppression," and they look in particular at one poem composed by a young person in the contemporary US that was performed at a school event for a "Student of Color (SOC) affinity group." Jean-Denis and Jocson advocate for "Healing-centered approaches" which prioritise young people's voices to "widen the learning and teaching spectrum for youth engagement in educational contexts"; they also express caution about "trauma-informed practice" in which young people are invited to write about trauma. They conclude by articulating important questions about "trauma-informed literacies among racialized youth," and about what young people can teach adults to "get past careless assumptions about who/how young people are or are supposed to be."

As these writers demonstrate, to engage with questions of trauma, intersectionality, and juvenilia requires specifying, broadening, and deepening our frames. Further specifying our frames is important to recognise how young people's intersecting identities may expose them to potential stress and trauma, such as that of racism and discrimination. Broadening is necessary so that young people whose lives converge with potentially traumatic situations are not limited and trapped within those frames. And deepening our frames can help account for young people's own interpretations and representations, including whether and how they consider their own experiences to have been potentially traumatic. 


\section{JJS December (202I) Special Issue: Juvenilia, Trauma, and Intersectionality WORKS CITED}

American Psychiatric Association. Diagnostic and Statistical Manual of Mental Disorders. $5^{\text {th }}$ ed. American Psychiatric Association, 2013.

Carter, Robert T. "Racism and Psychological and Emotional Injury: Recognizing and Assessing Race-Based Traumatic Stress." The Counseling Psychologist, vol. 35, no. 1, 2007, pp. 13-105. doi: 10.1177/0011000006292033.

Cho, Sumi, Kimberlé Williams Crenshaw, and Leslie McCall. "Toward a Field of Intersectionality Studies: Theory, Applications, and Praxis." Signs: Journal of Women in Culture and Society, vol. 38, no. 4, 2013, pp. 785-810.

Howard, Vanessa. "The Last Riot." THE VOICE of the Children, collected by June Jordan and Terri Bush. Holt, Rinehart, 1970, pp. 8-9.

Simmons, LaKisha. "The Poetry of Vesta Stephens: In Search of Black Girls' Gardens.” Tulsa Studies in Women's Literature, vol. 36, no. 2, 2017, pp. 449-61. Yeats, William Butler. The Collected Poems of W. B. Yeats. 1933. Macmillan, 1981. 